\title{
ALTERAÇÃO DO COMPORTAMENTO DOS ESTUDANTES DE GRADỦAÇÃO DA UNIVERSIDADE FEDERAL DE SANTA CATARINA (UFSĆ) EM RELAÇÃO AO CONSUMO DE SERVIÇOS DE STREAMIÑ G APÓS O INÍCIO DA PANDEMIA
}

\section{CHANGE IN BEHAVIOR OF UNDERGRADUATE STUDENTS AT THE FEDERAL UNIVERSITY OF SANTA CATARINA (UFSC) IN RELATION TO THE CONSUMPTION OF STREAMING SERVICES AFTER THE BEGINNING OF THE PANDEMIC}

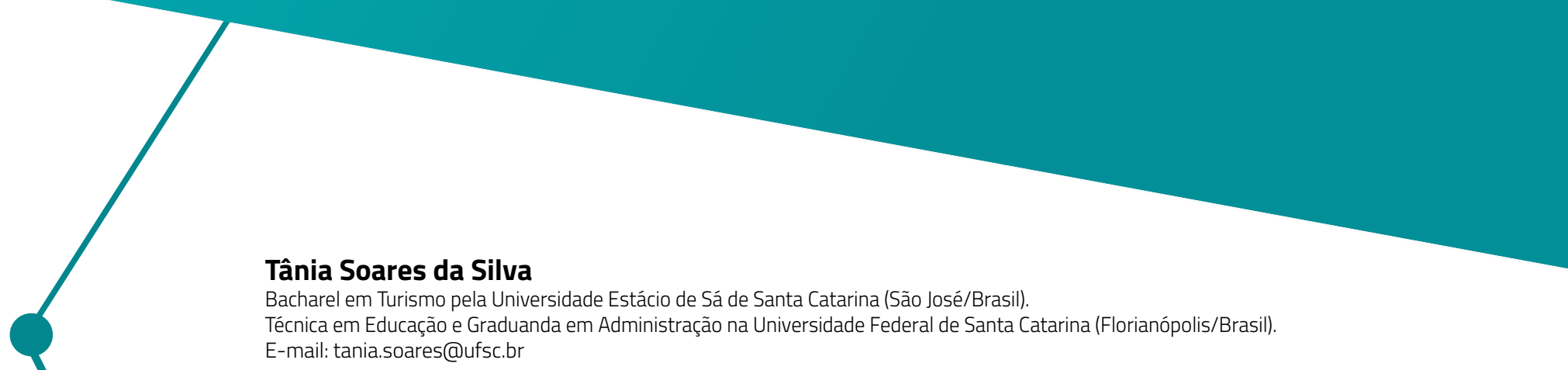

\section{Flora Moritz da Silva}

Doutora em Administração pela Universidade Federal de Santa Catarina (Florianópolis/Brasil). Pesquisadora do Núcleo de Inteligência Competitiva Organizacional em Marketing e Logística na Universidade Federal de Santa Catarina (Florianópolis/Brasil).

E-mail: floramds@gmail.com

\section{Thiago Oliveira Rodrigues}

Graduando em Administração pela Universidade Federal de Santa Catarina (Florianópolis/Brasil).

E-mail: thiago-1518@hotmail.com

\section{Helena Sigounas Muhammad}

Graduanda em Administração pela Universidade Federal de Santa Catarina (Florianópolis/Brasil).

E-mail: helenasigounas@hotmail.com 


\section{RESUMO}

A pandemia do novo coronavírus alterou a vida das pessoas de todo o mundo. Desde a execução de tarefas simples até as mais complexas, como as relações de trabalho e estudo, foram de alguma forma afetadas por esse novo cenário. Dentre as atividades/relações que sofreram alterações estão as de consumo e comportamento do consumidor. $O$ setor de entretenimento, tanto em casa quanto fora do lar, foi uma dessas atividades que mais sentiram essas alterações, conforme variados estudos vêm demonstrando. Assim, o presente artigo tem por objetivo verificar e analisar se houve uma mudança no comportamento de compra do corpo discente de graduação da Universidade Federal de Santa Catarina com relação ao consumo de serviços de streaming após o início da pandemia. Para isso, elaborou-se um questionário estruturado on-line que foi respondido por 574 estudantes de distintas fases e cursos. Com os resultados, verificou-se que houve uma alteração no consumo desses estudantes do período anterior à pandemia ao momento no qual houve pandemia e sugestão de medidas de isolamento. Dentre essas alterações, pode-se citar o conhecimento e assinatura de novas plataformas de streaming, assim como o aumento do número de horas e alteração dos dias, períodos e locais em que esses conteúdos passaram a ser consumidos.

Palavras-chave: Streaming. Pandemia. Alteração no Consumo. UFSC.

\section{ABSTRACT}

The new coronavirus pandemic has changed the lives of people around the world. From performing simple tasks to more complex ones, such as work and study relationships, they were somehow affected by this new scenario. Among the activities/relationships that have undergone changes are consumption and consumer behavior. The entertainment sector, both at home and away from home, was one of those activities that most felt these changes, as several studies have shown. Thus, this article aims to verify and analyze whether there was a change in the purchasing behavior of undergraduate students at the Federal University of Santa Catarina regarding the use of streaming services after the start of the pandemic. For this, a structured online questionnaire was developed, which was answered by 574 students from different phases and courses. With the results, it was found that there was a change regarding the use of these students from the period before the pandemic to the time when there was a pandemic and suggestion of isolation measures. Among these changes, we can mention the knowledge and subscription of new streaming platforms, as well as the increase in the number of hours and changes in the days, periods and places in which these contents started to be consumed.

Keywords: Streaming. Pandemic. Change in Consumption. UFSC. 


\section{INTRODUÇÃO}

Com o surgimento de tecnologias, como a internet e a evolução dos computadores e dispositivos eletrônicos, começa a ocorrer uma revolução na sociedade atual, haja vista que a mesma se encontra a cada dia mais conectada e com acesso irrestrito à informação.

As mídias tradicionais cada vez mais cedem espaço a novos recursos e ferramentas digitais, dentre eles os serviços de streaming, que se constitui em uma tecnologia que visa a troca de material em forma de áudio e/ou vídeo por meio de redes digitais (OLIVEIRA; RANIERI, 2017). Este serviço consiste na distribuição de conteúdo por meio de pacotes, não havendo armazenamento de conteúdo por parte do destinatário, sendo o conteúdo reproduzido na medida em que o usuário o recebe (FRANCISCO; VALENTE, 2016).

Uma pesquisa realizada pela Nielsen Brasil em parceria com a Toluna Influencers, revelou que 42,8\% dos brasileiros entrevistados assistem a conteúdos de streaming todos os dias, enquanto outros $43,9 \%$ têm essa prática ao menos uma vez por semana. Essa mesma pesquisa revela ainda que os serviços de streaming são consumidos ainda mais pelos jovens. $77,2 \%$ dos entrevistados que possuem entre 24 e 35 anos e $76,8 \%$ dos respondentes entre 16 e 23 se utilizam deste tipo de serviço (PORTAL NACIONAL DE SEGUROS, SAÚDE, INFO, TI, EDUCAÇÃO - SEGS, 2020).

Dentro desse cenário, ocorre ainda o surgimento de uma nova pandemia mundial que demanda medidas sanitárias de segurança, dentre elas, o isolamento social, fato que faz com que as pessoas permaneçam mais tempo em suas casas. Esse isolamento social, apesar de ocasionar inúmeras consequências negativas à sociedade, acarretou em um aumento da procura por serviços de streaming, pois as formas de lazer fora das residências se tornaram restritas e insalubres às pessoas. Segundo a empresa de inteligência integrada Conviva, os serviços de streaming cresceram 20\% globalmente em março de 2020 se comparados aos números do mês anterior e os gastos com plataformas digitais subiram durante o período da pandemia, apresentando alta de 5,2\% em relação ao mesmo período de 2019 (TUCCI, 2020).

Com base na pesquisa bibliográfica efetuada foi possível averiguar a falta de estudos sobre o referido assunto e, assim sendo, acredita-se que esse artigo torna-se relevante na medida em que pode agregar contribuições teóricas sobre o tema no país, principalmente no que tange ao comportamento do consumidor em relação ao mercado de streaming.

Portanto, o objetivo deste trabalho consiste em verificar se esse aumento global pela procura de serviços de streaming também se faz presente na comunidade discente da Universidade Federal de Santa 
Catarina (UFSC), assim como verificar se suas preferências, hábitos e nível de gastos também foram alterados durante esse período.

\section{SURGIMENTO DO STREAMING}

Até os anos de 1950 a única forma de ver um filme era ir até um cinema. Contudo, a partir dessa época, com a invenção dos transistores e tecnologias de videotape, foi possível o desenvolvimento de eletrônicos de maior qualidade. Esse fato permitiu a introdução dos aparelhos televisores nas residências, fazendo com que os filmes agora pudessem ser assistidos "no conforto dos lares" e, consequentemente, popularizando e disseminando essa forma de entretenimento por todo o mundo (OLIVEIRA et al., 2019).

A primeira fita magnética foi gravada pela Sony em 1973, sendo que o formato VHS permaneceu em uso até os anos 2000. Essa tecnologia, novamente reverteu a lógica desse tipo de entretenimento, pois, se antes os espectadores necessitavam sintonizar suas TVs na hora que a emissora propunha determinado programa ou filme, agora era o espectador que escolhia sua própria programação e hora em que gostaria de vê-la (OLIVEIRA et al., 2019).

Mais tarde outras tecnologias como o DVD, surgido em 1996, e o BluRay, de 2004, melhoraram ainda mais a definição de imagem e som, trazendo ainda mais qualidade para os consumidores (OLIVEIRA et al., 2019).

Já a invenção do rádio é atribuída ao italiano Guglielmo Marconi a partir de estudos sobre ondas eletromagnéticas que poderiam propagar-se no espaço. Sua primeira transmissão foi realizada em 1899, no Canal da Mancha (FERREIRA, 2013). O Brasil também está à frente dos primórdios do rádio, apesar de não ter sua participação reconhecida oficialmente. O padre Roberto Landell de Moura teria realizado em 1983 (dois anos antes de Marconi) transmissões de rádio, e em 1989 realizou a primeira transmissão de voz humana no Brasil. Ele patenteou um sistema fotônico-eletrônico no Brasil, em 1901 (ZALTRÃO, 2006).

O surgimento da rede mundial de computadores trouxe a possibilidade da transmissão do rádio via internet, aumentando a abrangência e alcance por parte das emissoras (FERREIRA, 2013). Em 1996, a rádio Itatiaia de Belo Horizonte, foi a primeira a iniciar uma transmissão de programação em tempo real via web, tornando-se a primeira emissora do Brasil a disponibilizar seu conteúdo de forma on-line. Finalmente, nos anos 2000, surgem as primeiras plataformas de streaming interativo (on demand), onde os consumidores procuram o conteúdo que desejam e "fazem a sua própria programação" (SANTOS, 2009).

De maneira efetiva, a popularização dos serviços de streaming se deu a partir do surgimento das redes sociais, em meados do ano de 2004 e, principalmente com a difusão dos serviços de compartilhamento de vídeos e músicas como o Youtube e de downloads de filmes como o Torrent (SILVA; DALL'ORTO, 2017). 


\section{MERCADO DE STREAMING}

Existem na atualidade, diversos modelos de negócios, entre os quais: assinatura, no qual o usuário paga um valor fixo para ter acesso ao conteúdo da plataforma; aluguel ou venda, em que o usuário navega gratuitamente pelo catálogo da plataforma, mas para ter acesso ao conteúdo deve pagar individualmente por cada conteúdo consumido; acesso gratuito, em que a plataforma oferece o serviço de forma gratuita e se mantém por meio do ganho com publicidade; acesso condicionado, onde a oferta de conteúdo depende de vínculo com outro serviço, como canais que disponibilizam conteúdos de suas grades de programação por um tempo determinado em uma plataforma específica (TENDÊNCIAS, 2016).

Um exemplo de como esses serviços vêm crescendo é o mercado da música nos EUA, onde as plataformas de streaming cresceram 13\% em 2019 (ISTOÉ DINHEIRO, 2020). No Brasil, uma pesquisa efetuada pela agência Opinion Box com 2.092 internautas revela que um em cada cinco brasileiros começaram a utilizar serviços de streaming de vídeo desde setembro de 2019, havendo um aumento de $12 \%$ nas assinaturas (OPINION BOX, 2020).

A mesma pesquisa mostra ainda quantos dos entrevistados assinam algum serviço de streaming. Enquanto no ano de 2019 64\% dos entrevistados assinavam algum tipo de serviço de streaming, em 2020 esse número saltou para 76\%. Outro fator abordado nessa pesquisa foram os principais fatores que influenciaram na decisão de compra de serviços de streaming nos anos de 2019 e 2020, sendo o preço o principal deles; além de mostrar os valores que os brasileiros costumam gastar para ter acesso aos serviços de streaming que assinam, conforme pode ser observado nas Figuras 1 e 2 .

\section{Figura 1 - Gastos por mês com streaming de vídeo}

$2020 \quad 2019$

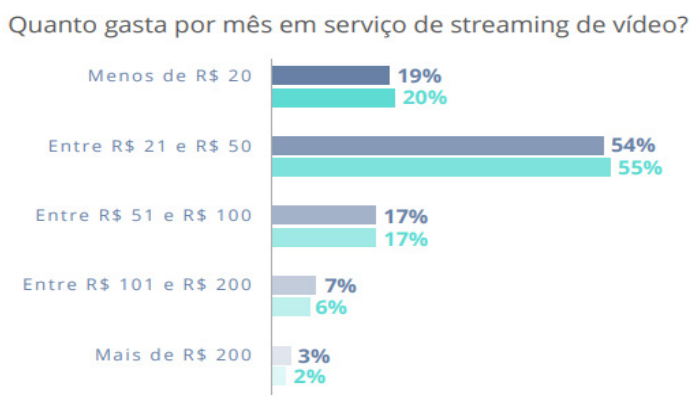

Fonte: Opinion Box (2020) 


\section{Gestãoe \\ Desenvolvimento}

e-ISSN: 2446-6875

p-ISSN: $1807-5436$

Figura 2 - Fatores influenciadores da compra

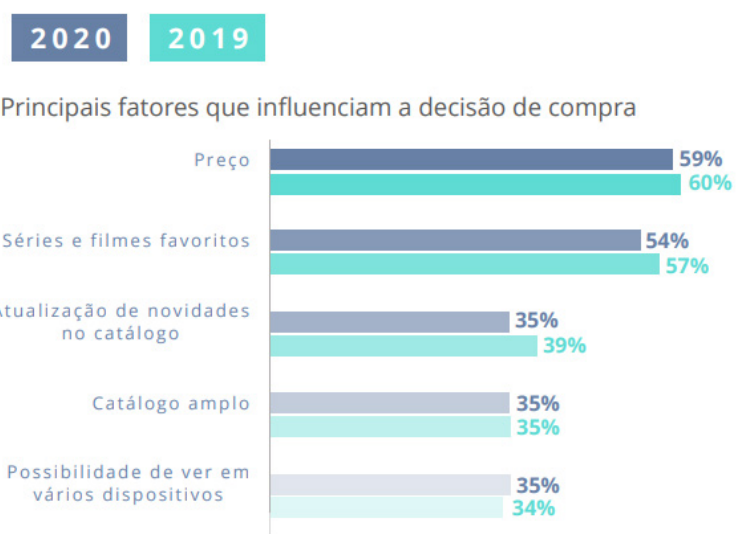

Fonte: Opinion Box (2020)

O relacionamento do cliente com a marca também foi abordado, assim como as marcas mais requisitadas pelos clientes. Para os mais de 2.000 brasileiros entrevistados, tanto a primeira marca a ser lembrada, quanto o serviço mais utilizado era a Netflix, conforme observa-se nas Figuras 3 e 4.

Figura 3 - 5 marcas mais lembradas

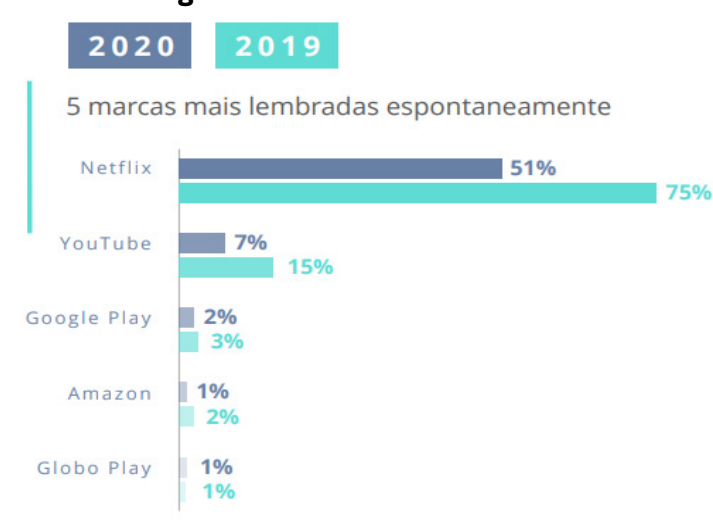

Fonte: Opinion Box (2020) 


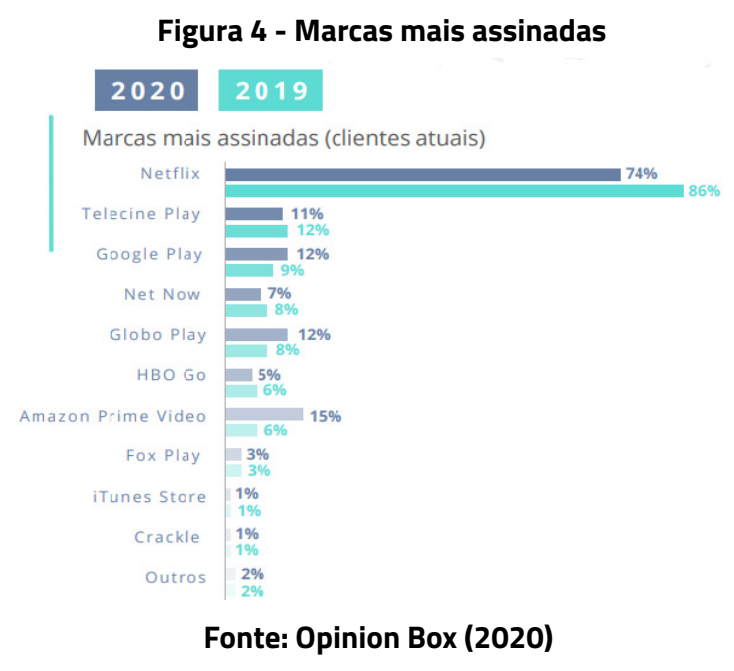

Especificamente no período da pandemia, segundo pesquisa da Nielsen Brasil em parceria com a Toluna Influencers, as plataformas de streaming de vídeo conquistaram espaço fixo na rotina dos brasileiros. $42,8 \%$ dos brasileiros entrevistados assistem conteúdos por streaming diariamente. Outros $43,9 \%$ consomem vídeos no formato pelo menos uma vez na semana e somente $2,5 \%$ declararam que nunca veem streamings (PORTAL NACIONAL DE SEGUROS, SAÚDE, INFO, TI, EDUCAÇÃO - SEGS, 2020). Assim sendo, estas pesquisas demonstram como os serviços de streaming vêm ganhando corpo perante os consumidores e expandindo suas fatias de mercado progressivamente.

\section{PROCEDIMENTOS METODOLÓGICOS}

Com o objetivo de conhecer uma possivel alteração no consumo, hábitos e preferências dos estudantes da UFSC com relação aos serviços de streaming no período posterior à pandemia, foi realizada uma pesquisa descritiva, que conforme Cervo e Bervian (1996, p. 49) "[...] observa, registra, analisa e correlaciona fatos ou fenômenos (variáveis) sem manipulá-los", tendo como principal objetivo descrever as "[...] características de determinada população ou fenômeno ou o estabelecimento de relações entre variáveis" (GIL, 1999, p. 44).

Utilizou-se uma abordagem direta, apresentando aos entrevistados o objetivo da pesquisa, e explícita na formulação das perguntas. O questionário é um instrumento de obtenção de informações de seus entrevistados, composto por um conjunto de perguntas estruturadas (MALHOTRA, 2006). Na presente pesquisa foi utilizado um questionário on-line, composto por uma pergunta aberta e 31 perguntas de múltipla escolha. A primeira questão se constituía em uma pergunta filtro para que se pudesse certificar 
que os respondentes pertenciam ao público-alvo do estudo. As próximas sete perguntas abordavam questões demográficas, com foco na caracterização do perfil dos respondentes. As perguntas restantes focaram-se nos hábitos de consumo de serviços de streaming pelos estudantes; sendo comparativas entre os períodos pré e pós o início da pandemia.

Com relação à amostra, utilizou-se amostragem não probabilística, adotando-se a técnica de amostragem por julgamento que, segundo Malhotra (2006), é uma forma de amostragem por conveniência em que os elementos da população são selecionados conforme o interesse do pesquisador, também chamada de amostragem acidental, consistindo na consulta a pessoas mais convenientes disponiveis para o estudo (POLIT; BECK; HUNGLER, 2004). Não se permite, portanto, generalizações.

Os questionários foram repassados de maneira on-line para todas as secretarias de cursos de graduação da UFSC, que, por sua vez, repassaram-nos aos alunos, e somente os que receberam e tiveram interesse em responder participaram da pesquisa. Foram obtidas 574 respostas, o que consiste em $2 \%$ da população pesquisada, que é de 28.524 alunos.

No que tange à coleta e análise de dados, antes de sua divulgação, os questionários passaram por pré-teste com cinco alunos de graduação da UFSC, que fizeram uma avaliação do mesmo e expuseram suas dúvidas e sugestões de melhoria para o instrumento. Devido à pandemia de coronavírus, os questionários do pré-teste foram enviados de maneira on-line aos respondentes, que posteriormente fizeram seus apontamentos também de maneira virtual.

Efetuados os devidos ajustes, os questionários elaborados pelo Google Forms foram enviados a todas as secretarias dos cursos de graduação da UFSC na segunda quinzena de novembro para que houvesse a divulgação via fórum aos alunos componentes da população. Os questionários ficaram disponíveis para receber respostas do dia 16 de novembro de 2020 ao dia 22 de novembro de 2020 . No total foram obtidas 574 respostas válidas. A ferramenta utilizada para a análise e tabulação dos dados foi a própria plataforma usada para a coleta de dados (Google Forms), do qual se obtiveram os gráficos apresentados.

\section{PREFERÊNCIAS E MUDANÇAS DE HÁBITOS NO CONSUMO DE SERVIÇOS DE STREAMING}

Nesta seção serão apresentados os resultados obtidos referentes ao perfil dos respondentes, preferências e mudanças de hábitos com relação ao consumo de serviço de streaming antes e após o início da pandemia. A aplicação do questionário foi efetuada de forma on-line por meio da ferramenta Google Forms. Através dos meios de divulgação da pesquisa, foi possível alcançar uma taxa de 98,1\% como pertencentes ao público alvo da pesquisa: estudantes de graduação da UFSC de variados cursos. 


\section{Figura 5 - Em que fase se encontra?}

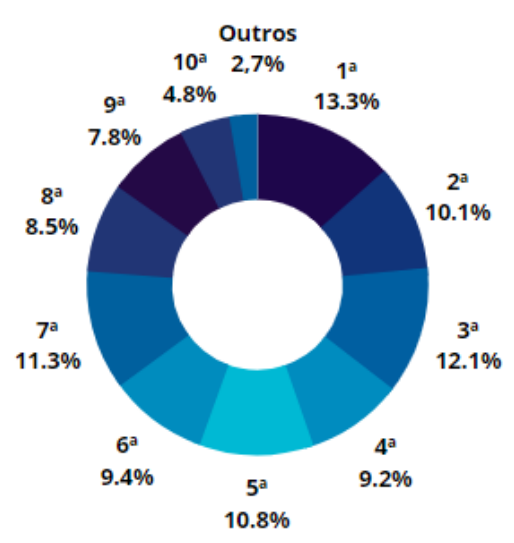

Fonte: Dados primários (2021)

Por meio da Figura 5 é possível observar que a pesquisa abrangeu estudantes de diversas fases de forma relativamente proporcional, fato que demonstra a variedade do público atingido.

\section{Figura 6 - Possui alguma outra ocupação além de ser estudante da UFSC?}

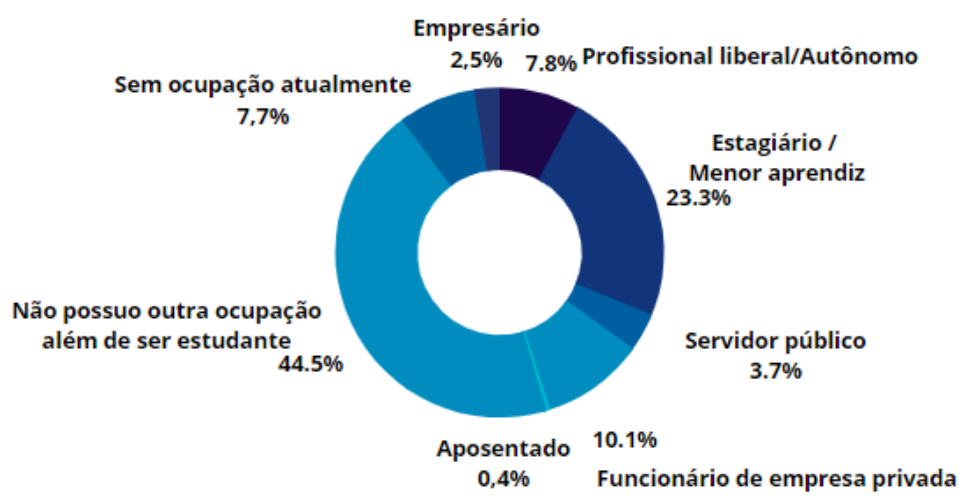

\section{Fonte: Dados primários (2021)}

Conforme apresentado na Figura 6, grande parte dos entrevistados, 44,5\% dos respondentes, são somente estudantes. E 23,3\% são estagiários, fato já esperado por tratar-se de um público universitário. 
Figura 7 - Qual a renda familiar mensal?

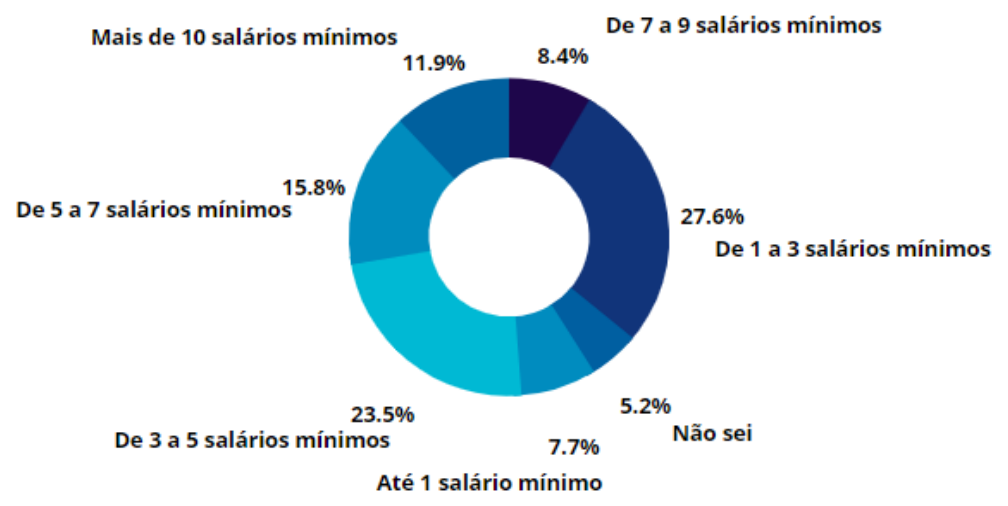

Fonte: Dados primários (2021)

Segundo a Figura 7, 27,6\% dos respondentes possuem renda familiar de 1 a 3 salários mínimos, 23,5\% possuem de 3 a 5 salários mínimos, 15,8\% possuem de 5 a 7 salários, 11,9\% possuem mais de 10 salários mínimos, 8,4\% possuem de 7 a 9 salários, 7,7\% possuem até 1 salário mínimo e 5,2\% não souberam responder.

O Instituto Brasileiro de Geografia e Estatística (IBGE) divide a população brasileira em cinco classes sociais de acordo com o rendimento familiar bruto mensal mensurado em salários mínimos: a classe $\mathrm{E}$ compreende famílias que recebem até dois salários mínimos; a classe $D$ vai de mais de dois até cinco salários; a classe C vai de mais de cinco a dez salários; a classe B compreende quem ganha mais de dez até vinte salários mínimos; e a classe $A$ engloba quem recebe mais de vinte salários mínimos (IBGE, 2020). Assim sendo, conforme classificação do IBGE, a maioria dos estudantes consultados pertence às classes De E.

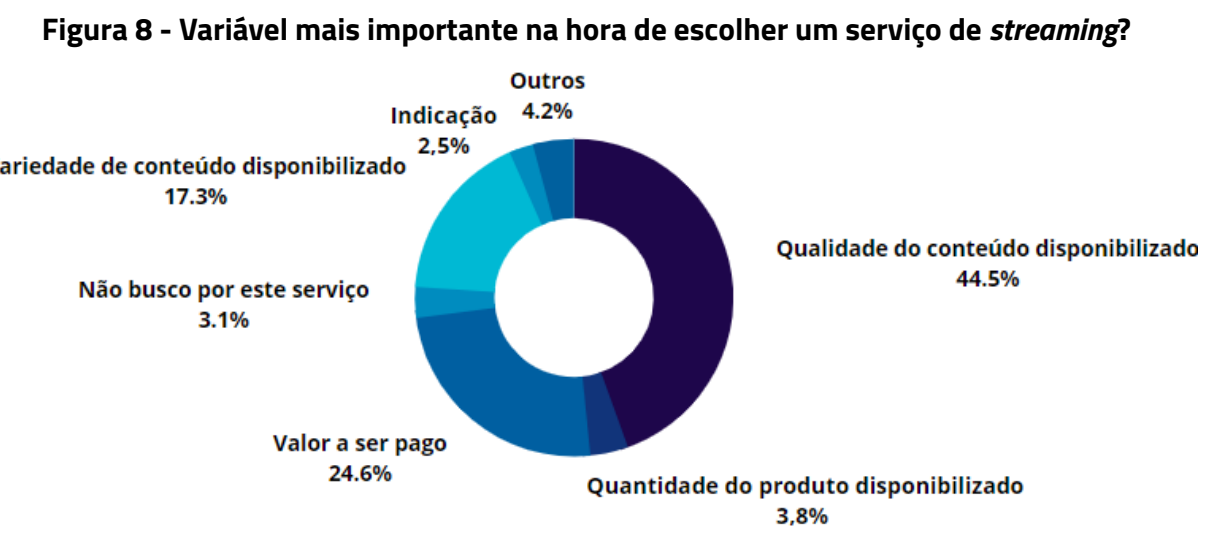

Fonte: Dados primários (2021) 
A Figura 8 apresenta as variáveis consideradas mais importantes no momento de se escolher um serviço de streaming, onde $44,5 \%$ dos respondentes cita a qualidade do conteúdo como principal variável para escolha do serviço de streaming. $24,6 \%$ citam o valor desembolsado. Diferentemente dos respondentes da pesquisa Opinion Box (2020), os estudantes da UFSC primam mais pelo fator qualidade na hora de escolher um streaming, em detrimento do preço, elemento mais citado naquela pesquisa.

Esse resultado corrobora com as ideias de Richers (1984), que relata que para a maioria dos consumidores a utilidade de um bem não resulta somente em características físicas, custos ou preço, mas as variáveis "imaginárias" associadas pelo consumidor ao bem como sensações, percepções, emoções, etc., também são consideradas importantes.

\section{Figura 9 - Quem paga pelo serviço?}

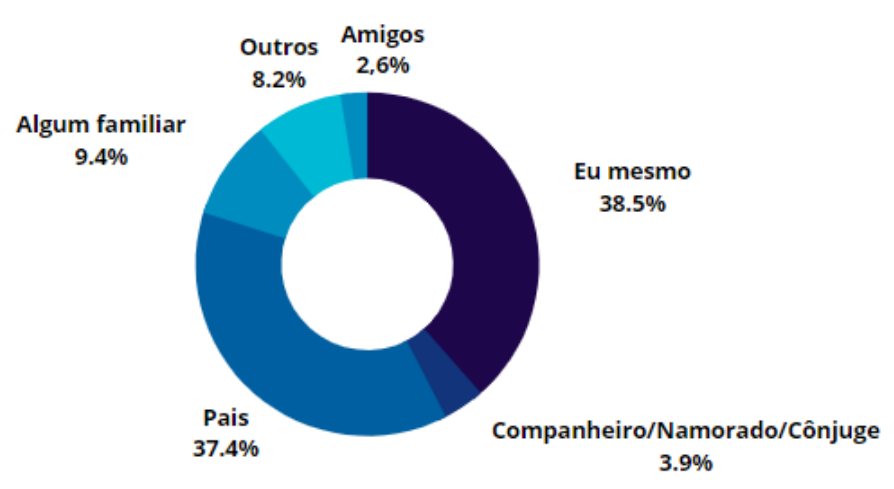

\section{Fonte: Dados primários (2021)}

Conforme apresentado na Figura 9, 38,5\% dos respondentes pagam pelo próprio serviço, em 37,4\% dos casos o serviço é pago pelos pais, e em 9,4\% por algum familiar. Os outros 14,7\% são pagos por amigos e companheiros, compartilham ou preferem não informar. Assim, pode-se observar que na maior porcentagem obtida $(38,5 \%)$ são os próprios respondentes que pagam pelo serviço. Porém, somandose a porcentagem dos que têm esse tipo de serviço pago por outras pessoas (que se constitui nos $61,5 \%$ restantes), observa-se que a maioria dos respondentes não paga pelos serviços de streaming que consome, fato que pode interferir nas preferências e escolhas dos serviços por parte dos respondentes. 


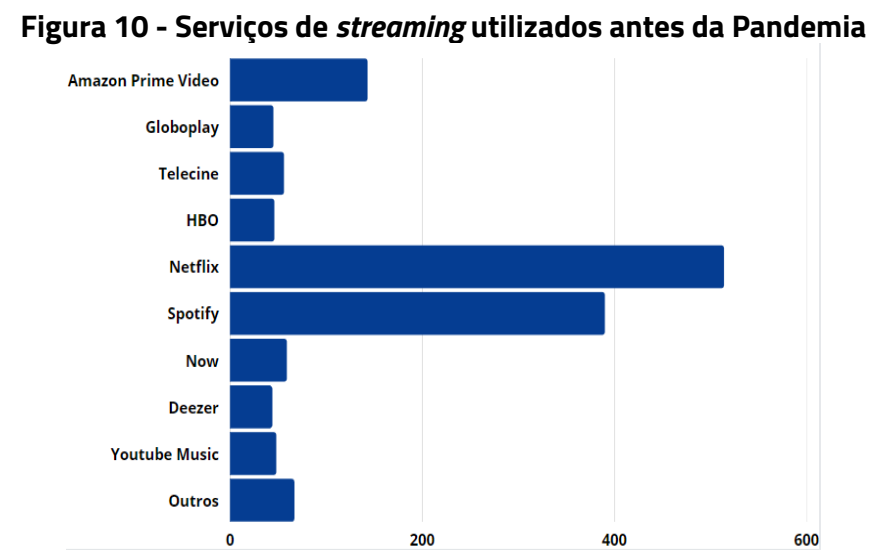

Fonte: Dados primários (2021)

Figura 11 - Serviços de streaming utilizados após o início da pandemia

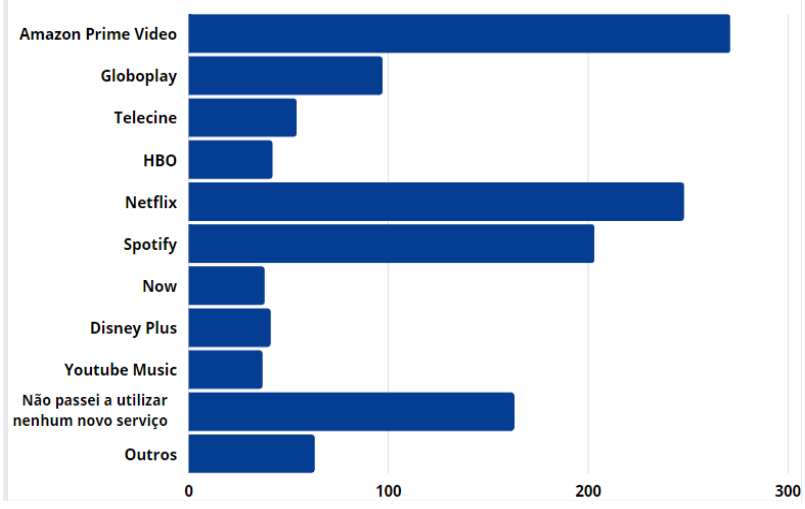

Fonte: Dados primários (2021)

A Figura 10 apresenta que, antes da pandemia, $514(91,3 \%)$ dos respondentes utilizavama plataforma de streaming Netflix, 390 (69,3\%) o Spotify, 143 (25,43\%) a Amazon Prime Video e 59 (10,5\%) utilizavam a plataforma Now. Além dos serviços de streaming com maiores índices de utilização, também foram citados outros serviços com utilização inferior a 10\% e 14 (2,5\%) dos respondentes citaram não utilizar nenhuma plataforma de streaming. Netflix e Spotify estão entre as principais plataformas utilizadas no período anterior à pandemia pelos estudantes de graduação da UFSC.

Após o início da pandemia, na Figura 11 vemos que 271 (48,1\%) respondentes começaram a utilizar a Amazon Prime Video como serviço de streaming, 248 (44\%) começaram a utilizar Netflix, 202 (35,9\%) começaram a utilizar o Spotify e $97(17,2 \%)$ começaram a utilizar a Globo Play. Outras plataformas como, Telecine, HBO, Now, Disney Plus, Amazon Music, Youtube Music entre outras, tiveram um percentual inferior a 10\% de novos usuários. $163(29 \%)$ dos respondentes informaram que não passaram a utilizar 
nenhuma nova plataforma de streaming e $8(1,4 \%)$ não utilizam nenhuma plataforma. Sendo assim, Amazon Prime Video e Netflix, foram as plataformas que tiveram maior aumento de usuários.

Este resultado não se constitui em um fato inesperado, tendo em vista que vários estudos, como os de Vieira e Costa (2021) ou Nunes (2015) apontam essas plataformas como as mais consumidas no Brasil.

Em comparação com a pesquisa Opinion Box (2020), os alunos da UFSC assinam em maior proporção serviços de streaming do que os entrevistados desta pesquisa. Enquanto 91,3\% dos alunos da UFSC assinavam algum tipo de streaming antes da pandemia, o percentual de pesquisados do Opinion Box que assinam streamings é de 76\% no início de 2020 e 64\% em 2019.

Segundo Soares (2020), esse aumento no uso das plataformas de streamingé uma das consequências da crise sanitária causada pela Covid19, tendo em vista que as produções de áudio e audiovisuais se tornaram "os olhos de muitos para as ruas", quando não se podia estar nela devido às recomendações de distanciamento social.

Figura 12 - Aparelhos eletrônicos utilizados antes da pandemia para acessar plataformas de streaming

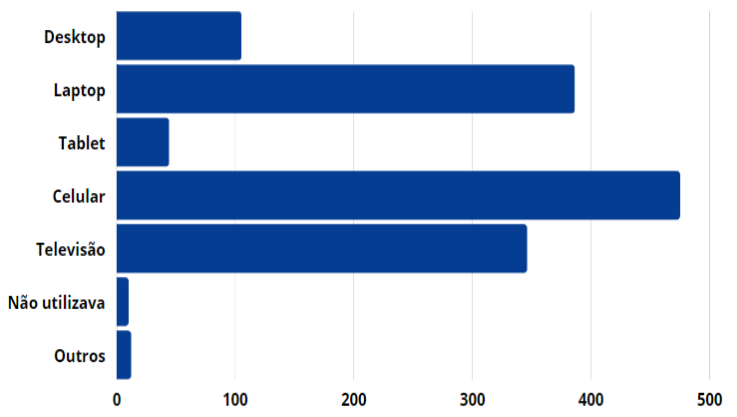

Fonte: Dados primários (2021)

Figura 13 - Aparelhos eletrônicos utilizados após o início da pandemia para acesso plataformas de streaming

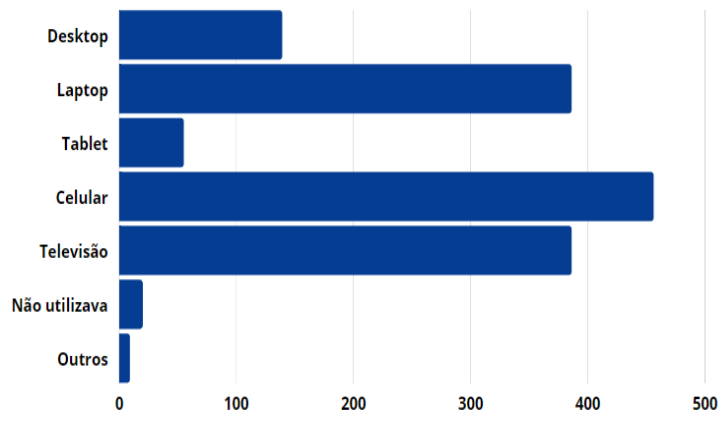

Fonte: Dados primários (2021) 
Na Figura 12 vemos que antes da pandemia, $475(84,4 \%)$ dos respondentes acessavam as plataformas de streaming através do aparelho celular, $383(68,6 \%)$ acessavam através do laptop, 346 $(61,5 \%)$ acessavam através da televisão, 104 (18,5\%) acessavam através do desktop, 44 (7,8\%) acessavam através do tablet. Menos de 1\% dos respondentes, acessavam por meio de outros aparelhos eletrônicos. $10(1,8 \%)$ dos respondentes informaram que não acessavam por nenhum aparelho.

A Figura 13 nos mostra que após o início da pandemia, 456 (81\%) dos respondentes informaram que utilizam o aparelho celular para acessar plataformas de streaming, $386(68,6 \%)$ utilizam a televisão, $386(68,6 \%)$ utilizam o laptop, $138(24,5 \%)$ utilizam o desktop, $55(9,8 \%)$ utilizam o tablet. Menos de $1 \%$ dos respondentes informaram que acessam as plataformas de streaming através de outros aparelhos eletrônicos. 20 (3,6\%) dos respondentes informaram que não acessam.

Sendo assim, as plataformas de streaming continuam sendo bastante acessadas, em sua maioria, através de aparelhos celulares, laptops e televisões, não havendo alterações significativas nesse quadro. Fazendo-se um paralelo com a pesquisa realizada pela Opinion Box (2020), citada no referencial teórico, os três primeiros dispositivos mais usados para o acesso aos streamings são exatamente os mesmos dos encontrados nesta pesquisa, na mesma importância de utilização.

Figura 14 - Produtos mais procurados no serviço de streaming antes da pandemia

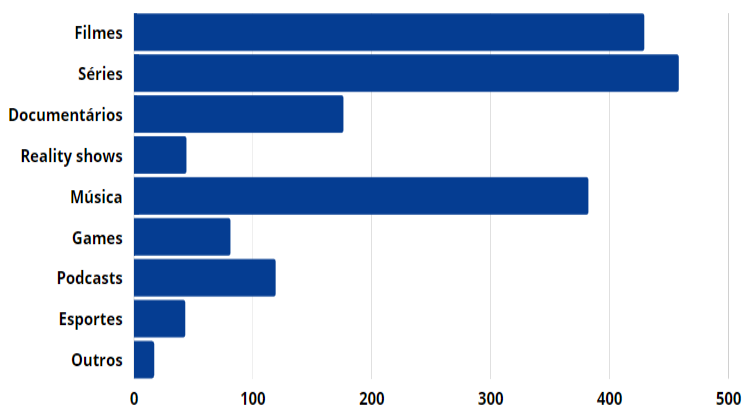

Fonte: Dados primários (2021) 


\section{Figura 15 - Produtos mais procurados no serviço de streaming após o início da pandemia}

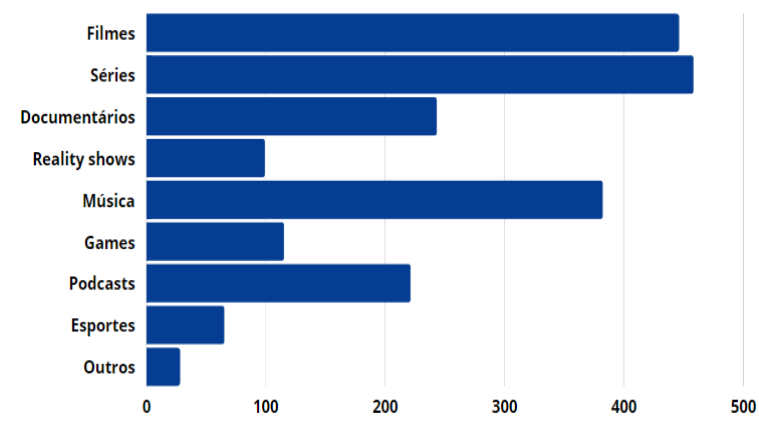

Fonte: Dados primários (2021)

Segundo a Figura 14, antes da pandemia, 458 (81,3\%) dos respondentes buscavam por séries nas plataformas de streaming, 428 (76\%) buscavam por filmes, 382 (67,9\%) buscavam por música, 176 (31,3\%) buscavam por documentários, 119 (21,1\%) buscavam por podcasts, $81(14,4 \%)$ buscavam por games e menos de $10 \%$ dos respondentes buscavam outros produtos. $11(2, \%)$ dos respondentes informaram que não buscavam nenhum produto.

Após o início da pandemia, na Figura 15, vemos que 458 (81,3\%) dos respondentes buscam por séries nas plataformas de streaming, 446 (79,2\%) buscam por filmes, 382 (67,9\%) buscam por música, 243 $(43,2 \%)$ buscam por documentários, 221 (39,3\%) buscam por podcasts, $115(20,4 \%)$ buscam por games, $99(17,6 \%)$ buscam por reality shows e $65(11,5 \%)$ buscam por esportes. $15(2,7 \%)$ dos respondentes informaram que não buscam por nenhum produto. Portanto, os três primeiros produtos mais procurados nas plataformas de streaming após o início da pandemia continuam sendo as séries, filmes e músicas. Uma mudança que pode ser notada é no produto "documentários", que partiu de 31,3\% para 43,2\% após o início da pandemia. 0 mesmo ocorreu com os podcasts (de 21,1\% para 39,3\%).

Esses dados corroboram com a pesquisa feita com 1.012 pessoas pela prestadora de serviços KPMG, que revela que o tipo de conteúdo mais importante no momento de escolha de um streaming, de fato, são as séries, com 37\% dos apontamentos (MONTEIRO, 2021). 


\section{Figura 16 - Valor pago pelo serviço de streaming antes da pandemia}

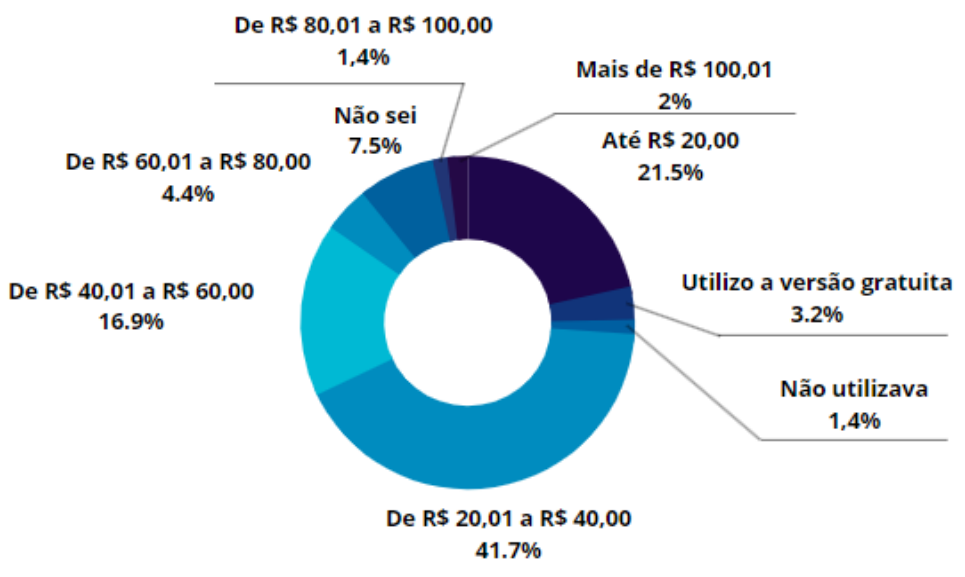

Fonte: Dados primários (2021)

Conforme a Figura 16 a maior parte dos respondentes gastavam, antes da pandemia, entre $\mathrm{R} \$ 20,01$ a $\mathrm{R} \$ 40,00$ com serviços de streaming.

Figura 17 - Valor pago pelo serviço de streaming depois da pandemia

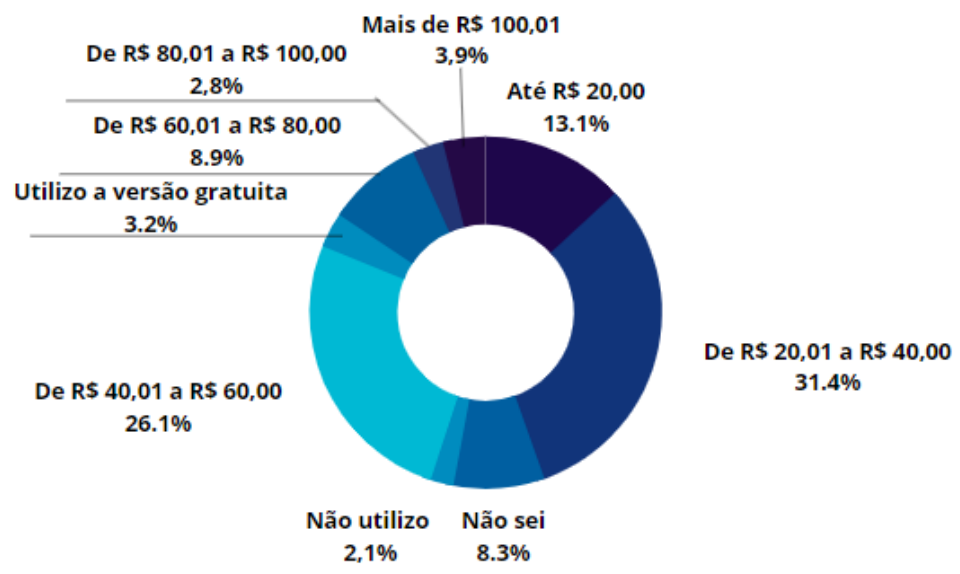

Fonte: Dados primários (2021) 
E após o início da pandemia, como apresenta a Figura 17, a maioria dos respondentes continua gastando entre $\mathrm{R} \$ 20,01$ a $\mathrm{R} \$$ 40,00 com serviços de streaming. Porém, nota-se uma queda da porcentagem das pessoas que gastavam de $R \$ 20,01$ a $R \$ 40,00$ antes da pandemia, de 41,7\% para 31,4\%. Essa se constitui na única exceção, pois todas as outras faixas de preço registraram aumento durante o período da pandemia. Apesar de não apresentarem o mesmo intervalo de classe, a pesquisa da Opinion Box (2020) registrou o mesmo que esta pesquisa. Enquanto nesta pesquisa a maioria dos entrevistados gasta entre $R \$ 20,01$ e $R \$ 40,00$ por mês com serviços de streaming. Os respondentes da pesquisa Opinion Box, em sua maioria, gastam entre $R \$ 21,00$ e $R \$ 50,00$, configurando-se em uma convergência de opiniões entre os respondentes.

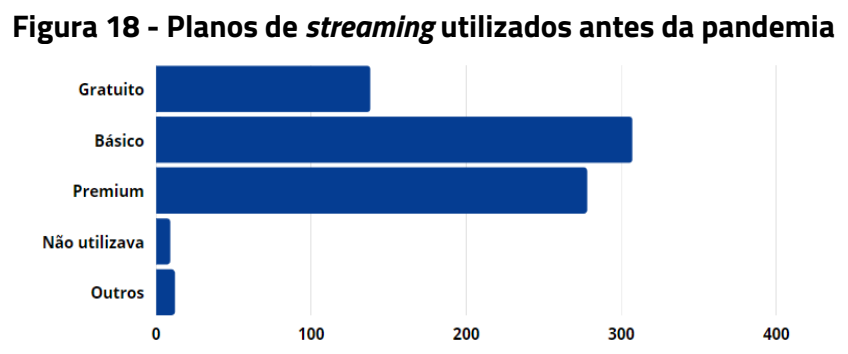

Fonte: Dados primários (2021)

Figura 19 - Planos de streaming utilizados após o início da pandemia

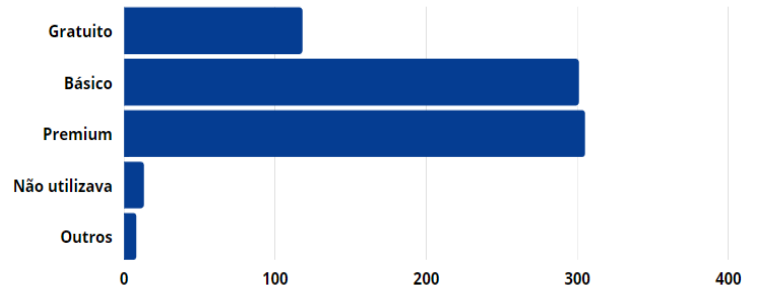

Fonte: Dados primários (2021)

Na Figura 18 vemos que antes da pandemia, 307 (54,5\%) dos respondentes utilizavam o plano Básico de streaming, 278 (49,4\%), utilizavam o plano Premium, 138 (24,5\%) utilizavam o plano gratuito, e $0,4 \%$ utilizavam outros. $9(1,6 \%)$ dos respondentes informaram que não utilizavam serviço de streaming.

Após o início da pandemia a Figura 19 apresenta que, 305 (54,2\%) dos respondentes utilizam o plano premium de streaming, 301 (53,5\%), utilizam o plano Básico, 118 (21\%) utilizavam o plano gratuito, e 0,4\% utilizavam outros. $13(2,3 \%)$ dos respondentes informaram que não utilizam o serviço de streaming. Isso significa uma mudança de cenário, pois a maioria dos respondentes informou utilizar o plano Premium nas plataformas de streaming, ao contrário do período anterior à pandemia onde o mais comum era a 


\section{Gestãoe \\ Desenvolvimento}

assinatura básica, com 54,5\%. Porém, cabe salientar que os percentuais de diferença entre os períodos antes e após o início da pandemia são bastante modestos, partindo de 54,5\% para 53,5\% no plano básico e $49,4 \%$ para $54,2 \%$ no plano premium.

Figura 20 - Horas de consumo semanais de serviços de streaming antes do início da pandemia

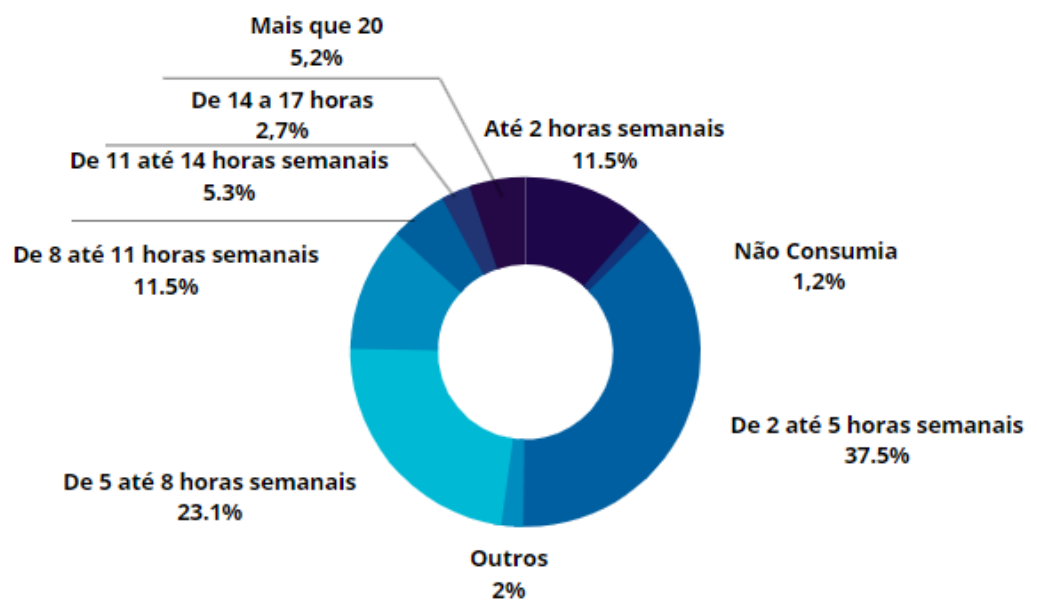

Fonte: Dados primários (2021)

A Figura 20 apresenta que antes da pandemia, 37,5\% dos respondentes consumiam os serviços de streaming de 2 até 5 horas por semana, 23,1\% de 5 até 8 horas por semana, 11,5\% até 2 horas por semana, $11,5 \%$ de 8 até 11 horas por semana. 0 restante dos entrevistados consumia mais de 11 horas semanais e 1,2\% dos respondentes informaram que não consumiam serviços de streaming antes da pandemia.

Figura 21 - Horas de consumo semanais de serviços de streaming depois da pandemia

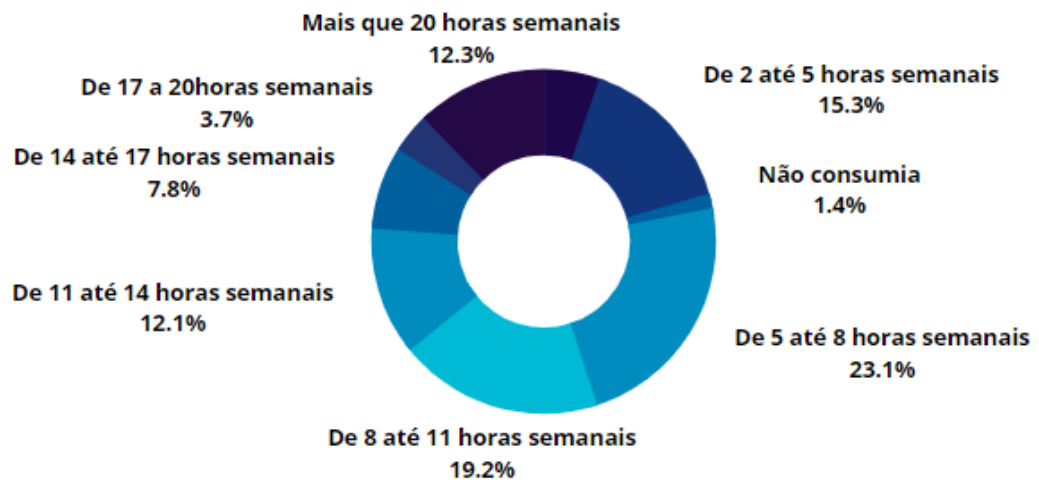

Fonte: Dados primários (2021) 
Já a Figura 21 traz que após o início da pandemia, 23,1\% dos respondentes consomem os serviços de streaming de 5 até 8 horas por semana, 19,2\% de 8 até 11 horas por semana, 15,3\% de 2 até 5 horas por semana, $12,3 \%$ mais de 20 horas por semana, $12,1 \%$ de 11 até 14 horas por semana e o restante mais de 14 horas semanais. 1,4\% dos respondentes informaram que não consomem serviços de streaming após o início da pandemia. Portanto, pode-se observar um aumento do consumo de streaming após o início da pandemia, tendo em vista que anteriormente a resposta mais recorrente era "de 2 a 5 horas", e após o início da pandemia esse número mudou para "de 5 até 8 horas por semana".

Esse aumento do número de horas dedicadas aos streamings corrobora com a pesquisa da Kantar IBOPE Media, que revela que 58\% dos usuários de internet afirmaram ver mais vídeos e TV on-line em plataforma de streaming durante os períodos de isolamento. 0 tempo em frente à televisão aumentou 37 minutos diários e cada indivíduo passou cerca de 1:49 horas por dia assistindo a conteúdos em plataformas de streaming (SILVA, 2021.)

Figura 22 - Dias da semana que ocorrem o consumo de streaming antes da pandemia

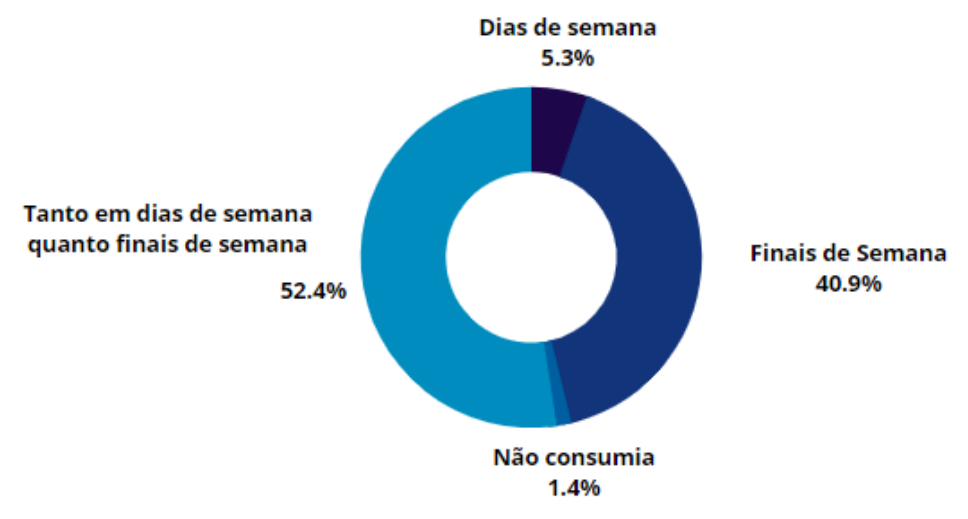

Fonte: Dados primários (2021)

A Figura 22 mostra que antes da pandemia, 52,4\% dos respondentes costumavam consumir os serviços de streaming tanto em dias de semana quantos aos finais de semana, 40,9\% somente durante os finais de semana e 5,3\% somente durante os dias da semana. 1,4\% dos respondentes informaram que não consumiam serviços de streaming antes da pandemia. 


\section{Gestãoe \\ Desenvolvimento}

Figura 23 - Dias da semana que ocorrem o consumo de streaming depois da pandemia

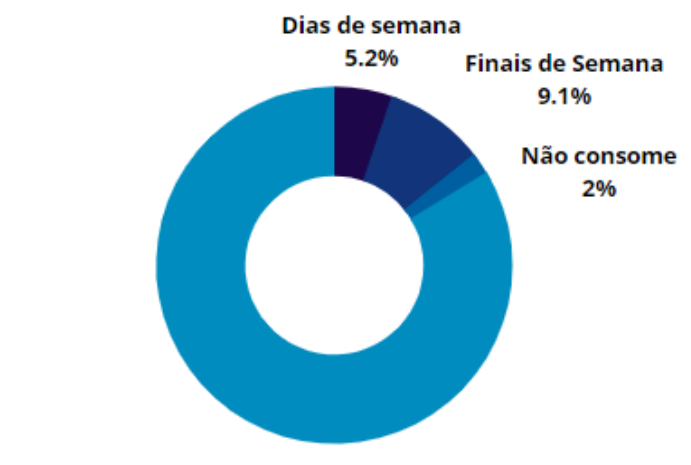

$83.7 \%$

Tanto em dias de semana

quanto finais de semana

\section{Fonte: Dados primários (2021)}

Já após o início da pandemia, conforme apresentado na Figura 23,83,7\% dos respondentes costumam consumir os serviços de streaming tanto em dias de semana quantos aos finais de semana, $9,1 \%$ costumam consumir durante os finais de semana e 5,2\% costumam consumir durante os dias da semana. $2 \%$ dos respondentes informaram que não consomem serviços de streaming após o início da pandemia.

Assim, a maioria dos respondentes consomem os serviços de streaming tanto em dias de semana quanto aos finais de semana. Apesar de se manterem os resultados de antes da pandemia, é importante salientar que a porcentagem de pessoas que assistiam tanto em finais de semana quanto em dias de semana saltou de $52,4 \%$ para $83,8 \%$.

Figura 24 - Período de acesso diário de serviços de streaming antes da pandemia

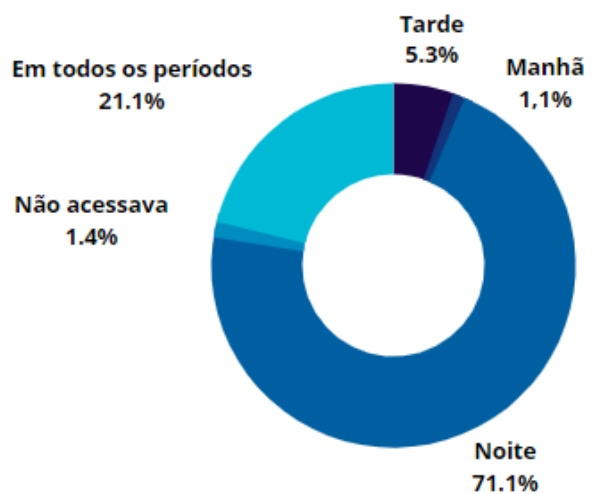

Fonte: Dados primários (2021) 
A Figura 24 mostra que antes da pandemia $71,1 \%$ dos respondentes acessavam serviços de streaming durante o período noturno, 21,1\% durante todos os períodos, 5,3\% durante o período da tarde e $1,1 \%$ no período da manhã. $1,4 \%$ dos respondentes informaram que não acessavam os serviços de streaming antes da pandemia.

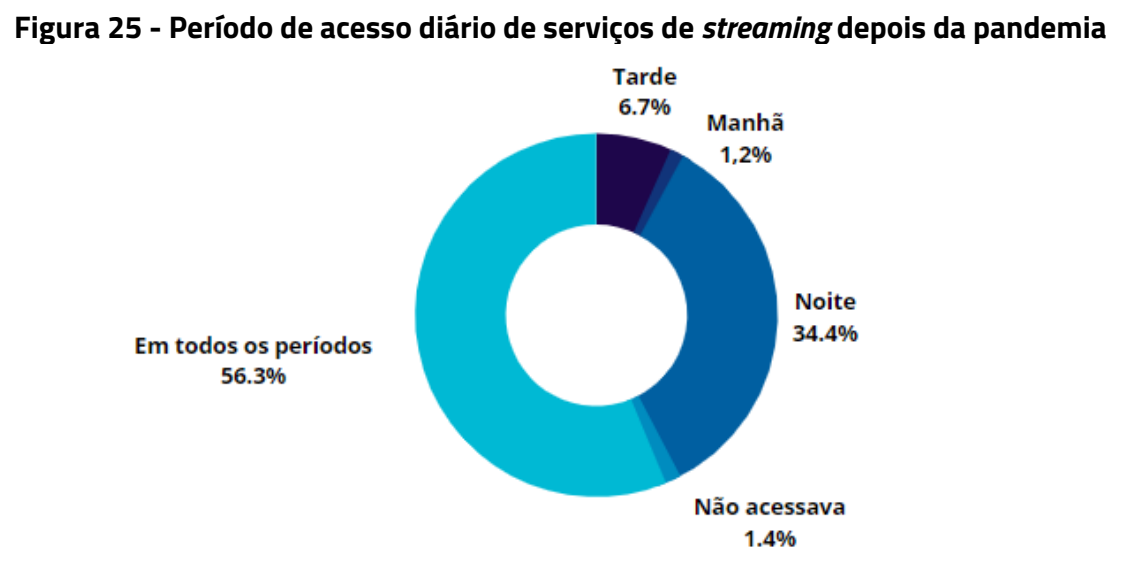

\section{Fonte: Dados primários (2021)}

Já após o início da pandemia, na Figura 25 vemos que 56,3\% dos respondentes costumam acessar os serviços de streaming durante todos os períodos do dia, 34,4\% costumam acessar durante o período noturno, 6,7\% costumam acessar durante o período da tarde e 1,2\% costumam acessar no período da manhã. 1,4\% dos respondentes informaram que não acessam serviços de streaming após o início da pandemia. Com isso, nota-se uma mudança de comportamento, pois após o início da pandemia, a maioria dos respondentes afirmou que costuma acessar os serviços de streaming durante todos os períodos do dia, diferentemente do período anterior ao da pandemia, onde se costumava acessar mais esses serviços durante o período noturno.

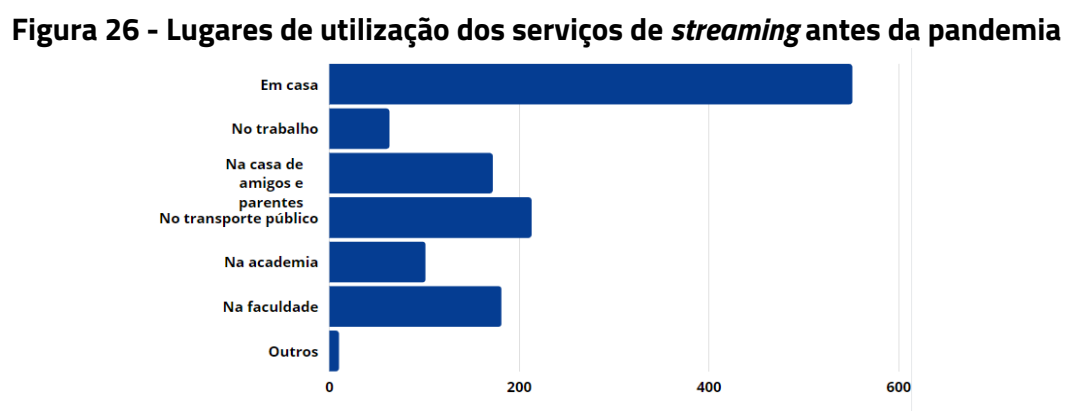

Fonte: Dados primários (2021) 


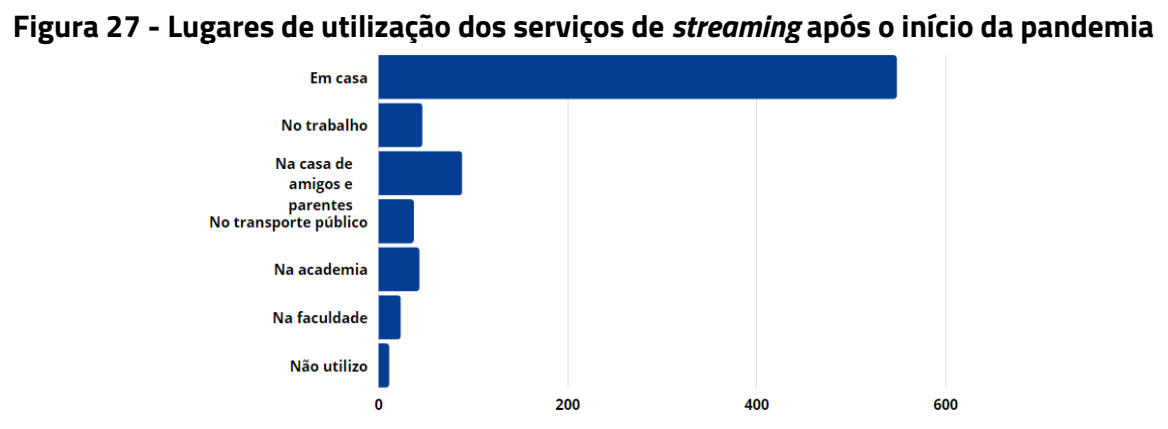

Fonte: Dados primários (2021)

Na Figura 26 temos que antes da pandemia, $551(97,9 \%)$ dos respondentes costumavam utilizar os serviços de streaming em casa, $213(37,8 \%)$ no transporte público, $181(32,1 \%)$ na faculdade, $172(30,6 \%)$ na casa de amigos e parentes, $101(17,9 \%)$ na academia, $63(11,2 \%)$ no trabalho e $0,2 \%$ em outros lugares. $7(1,2 \%)$ dos respondentes informaram que não utilizavam os serviços de streaming antes da pandemia.

Segundo Burnay e Ribeiro (2016), esse comportamento é comum quando se trata de jovens, pois se as gerações mais velhas mantêm a televisão e a sala de estar como o principal meio e local de consumo de conteúdos de entretenimento audiovisual, as gerações mais novas, maioria da população deste estudo, apresentam maior variação dos locais onde consomem esse tipo de conteúdo.

Contudo, percebe-sena Figura 27 queapós o início da pandemia, 97,3\% dos respondentes começaram a utilizar os serviços de streaming em casa, 15,6\% na casa de amigos e parentes, 8,2\% no trabalho, 7,6\% na academia, 6,6\% no transporte público e $4,1 \%$ na faculdade. $2 \%$ dos respondentes informaram que não passaram a utilizar serviços de streaming após o início da pandemia. Sendo assim, após o início da pandemia, a maioria dos respondentes continua a utilizar os serviços de streaming em casa. Porém, notase uma expressiva queda do uso no transporte público, que passou de 37,8\% para 6,6\% após o início da pandemia, e na faculdade, que foi de $32,1 \%$ antes da pandemia para $4,1 \%$, tendo em vista que desde 0 início de 2020 a UFSC mantém suas atividades em modo remoto para a grande maioria dos alunos. 
Figura 28 - Principal motivação para o uso dos serviços de streaming antes da pandemia

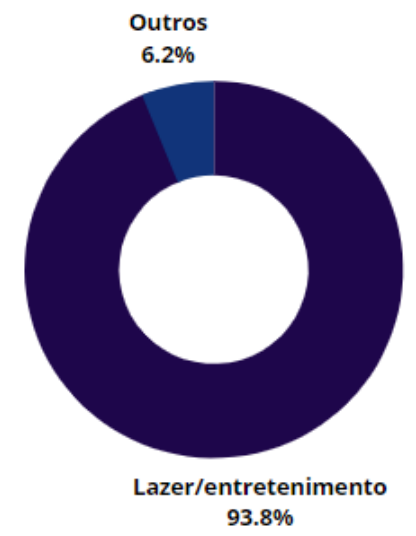

Fonte: Dados primários (2021)

A Figura 28 nos mostra que antes da pandemia, 93,8\% dos respondentes tinham como principal motivação para utilização dos serviços de streaming o lazer e entretenimento, enquanto 6,2\% tinham outras motivações.

Figura 29 - Principal motivação para o uso dos serviços de streaming depois da pandemia

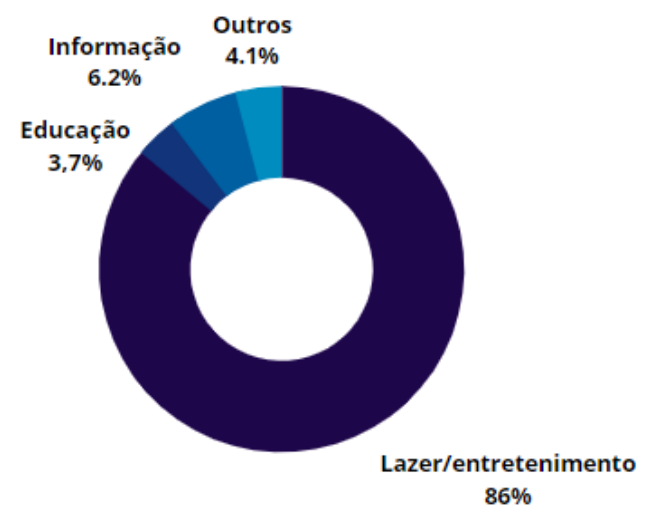

\section{Fonte: Dados primários (2021)}

Após o início da pandemia, 86\% dos respondentes têm como principal motivação para utilização dos serviços de streaming o lazer e entretenimento, 6,2\% buscam por informação, 3,7\% por educação e 4,1\% possuem outros motivos ou não acessam, segundo a Figura 29. Sendo assim, após o início da pandemia, a principal motivação para utilização dos serviços de streaming continua sendo o lazer e entretenimento, porém houve uma queda nessa taxa, que foi de $93,8 \%$ para $86 \%$. A motivação por busca por informações aumentou de $2,7 \%$ para $6,2 \%$ e assuntos relacionados à educação de $1,6 \%$ para $3,7 \%$. 
Figura 30 - Principal forma de entretenimento antes da pandemia

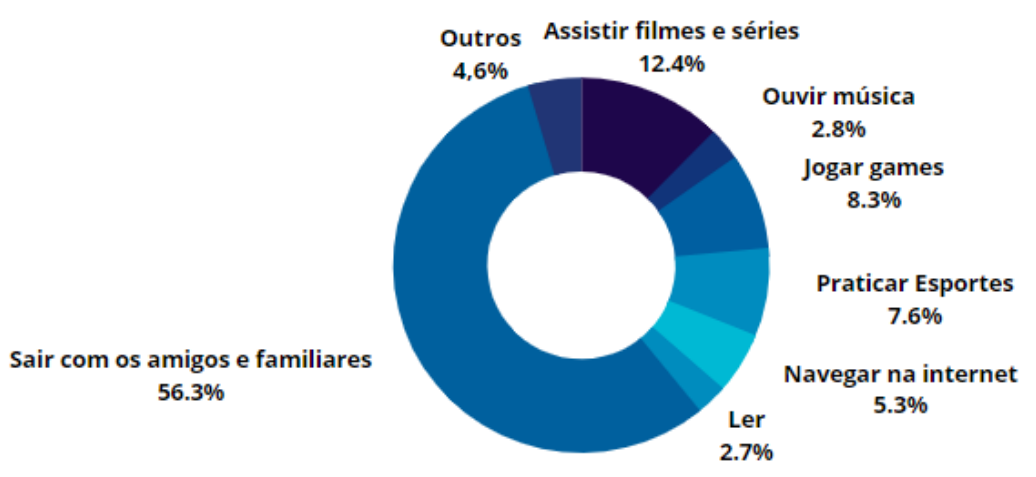

Fonte: Dados primários (2021)

Observando a Figura 30, vemos que antes da pandemia, 56,3\% dos respondentes tinham como principal forma de entretenimento sair com os amigos e familiares, $12,4 \%$ assistir filmes e séries, 8,3\% jogar games, 7,6\% praticar esportes, 5,3\% navegar na internet, 4,6 outros, 2,8\% ouvir músicas e 2,7\% leitura.

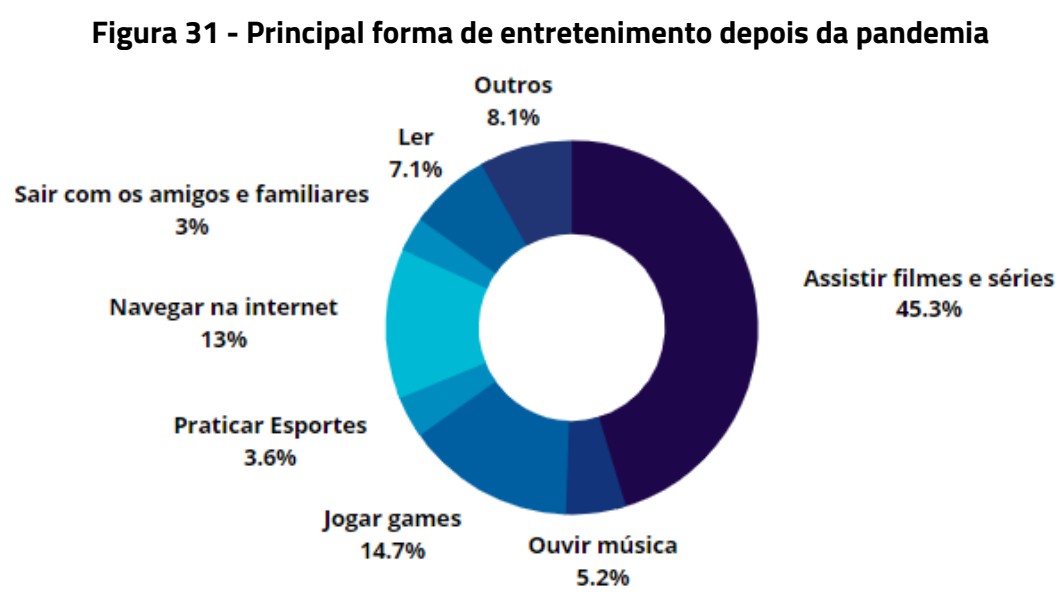

Fonte: Dados primários (2021)

E após o início da pandemia, como observado na Figura 31, 45,3\% dos respondentes têm como principal forma de entretenimento assistir filmes e séries, 14,7\% jogar games, 13\% navegar na internet, $7,1 \%$ leitura, 5,2\% ouvir músicas, 3,6\% praticar esportes, 3\% sair com amigos e familiares. 8,1\% utilizam outras formas de entretenimento. Sendo assim, após o início da pandemia, a principal forma de entretenimento, que antes era sair com os amigos e familiares, foi trocada por assistir filmes e séries. Essa informação vem ao encontro da pesquisa realizada por Acevedo et al. (2021) que após entrevistas em profundidade com 
27 indivíduos e survey com 256 respostas válidas, destacam que, de fato, o streaming se tornou a principal forma de lazer dos respondentes durante a pandemia.

\section{CONSIDERAÇÕES FINAIS}

A presente pesquisa teve por objetivo verificar se houve mudança no consumo e hábitos dos estudantes de graduação da UFSC com relação aos serviços de streaming no período após o início da pandemia. Para isso, foi formulado um questionário com 32 questões de múltipla escolha visando conhecer os hábitos dos acadêmicos de graduação da UFSC com relação ao consumo de streamings, fazendo-se um comparativo entre o período precedente à pandemia e o período após o início da pandemia.

A amostra utilizada foi a não probabilística, fato que inviabiliza a generalização dos dados coletados para toda a população escolhida. No entanto, devido ao alto percentual de respostas obtidas, 574 , que corresponde a $2 \%$ da população total escolhida, acredita-se que a pesquisa possa dar indícios consistentes sobre o comportamento da população. Some-se a isso, ainda, a grande variedade do perfil de respondentes, que se dividiram quase que equiparadamente em termos de gênero, renda familiar, fase em que se encontram na graduação e cursos aos quais pertencem. Os questionários dessa etapa foram distribuídos por meio das secretarias de curso aos alunos de graduação também de maneira on-line.

Assim sendo, pode-se observar que os hábitos dos estudantes da UFSC com relação aos serviços de streaming foram, de fato, modificados após o início da pandemia. Antes da pandemia, a maioria dos alunos usava a plataforma Netflix (91,3\%) e Spotify $(69,3 \%$ ) e somente $25,43 \%$ utilizavam a Amazon Prime Video. Após o início da pandemia, 48,1\% dos respondentes começaram a usar a Amazon Prime e somente $35,9 \%$ começaram a usar Netflix.

Outro aspecto consultado foi com relação ao valor despendido na aquisição dos serviços. Apesar de os valores mais citados continuarem sendo o intervalo de $\mathrm{R} \$ 20,01$ a $R \$ 40,00$, é importante salientar que se notou uma queda nessa porcentagem, de 41,7\% para 31,4\% após o início da pandemia, e um aumento entre as pessoas que gastavam entre $\mathrm{R} \$ \mathrm{R} \$ 40,01$ e $\mathrm{R} \$ 60,00$ antes da pandemia de $16,9 \%$ para $26,1 \%$, o que leva a crer que uma percentagem de pessoas migrou de um gasto mais modesto, para outro mais oneroso.

Como a migração para planos mais caros não foi constatada, pois o percentual de variação de migração entre planos foi baixa, acredita-se que os respondentes, ao aumentar seus gastos com streaming, tenham assinado planos com novas plataformas e não dado upgrade nas plataformas que já possuíam.

As horas de consumo de streaming também sofreram alterações durante a pandemia. Antes da pandemia grande parte dos entrevistados passava de 2 a 5 horas consumindo streaming (37,5\%), agora 0 
percentual mais expressivo são dos que passam de 5 a 8 horas consumindo os serviços. A porcentagem de pessoas que consumia de 2 a 5 horas caiu de 37,5\% para 15,3\%, enquanto que a de 8 a 11 horas aumentou de $11,5 \%$ para $19,2 \%$.

Com relação aos dias em que os serviços eram e agora são consumidos, 52,4\% dos respondentes costumavam consumir serviços de streaming tanto em dias de semana quanto aos finais de semana e 40,9\% tinham o costume de consumi-los somente aos finais de semana. Com o início da pandemia, o percentual de pessoas que começou a utilizar streamings tanto em dias de semana quanto em finais de semana cresceu para $83,8 \%$ e o percentual de pessoas que consome somente aos finais de semana diminuiu para 9, $1 \%$.

Um dos hábitos que mudou drasticamente foi com relação aos horários em que os serviços de streaming passaram a ser consumidos. Se antes a maioria alegava que só consumia esse tipo de serviço no período noturno $(71 \%)$, agora somente $34,3 \%$ alegam o fazer ainda. Os respondentes que acessaram a qualquer hora do dia passaram de $21,1 \%$ para $56,1 \%$.

Apesar dos respondentes continuarem a acessar os serviços de streaming basicamente em casa, notou-se uma expressiva queda do uso no transporte público (de $37,8 \%$ para 6,6\%), e na faculdade (de $32,1 \%$ para $4,1 \%$ ). Um dos tópicos que mais se diferenciam no período pré e pós-início da pandemia foi com relação às formas de divertimento desses alunos. Se antes a realidade para muitos era sair com os amigos e familiares $(56,3 \%)$, agora a realidade para grande parte deles é o divertimento dentro do lar, assistindo a filmes e séries $(45,3 \%)$.

Aspectos que tiveram pouca variação foram relacionados aos conteúdos mais acessados que continuaram a ser filmes e séries. Os aparelhos utilizados para acessar tais serviços também não variaram, continuando a serem os celulares, os laptops e os televisores. A principal motivação para a procura de streamings continua sendo o lazer e entretenimento. Portanto, considera-se que a pesquisa, apesar de não possuir amostra probabilística, pode ser tomada como um gerador de indícios sobre o comportamento dos estudantes de graduação da UFSC com relação ao consumo de streamings antes e após o período pandêmico.

Por hora, este estudo oferece algumas informações relevantes para que gestores e marketeers da indústria de streaming possam dirigir seus esforços promocionais de maneira mais eficiente, haja vista que o público jovem, população-alvo deste estudo, se constitui em grande parcela dos consumidores desse conteúdo (ALVES, 2018) (OPINION BOX, 2020).

Futuramente, pode ser interessante explorar o comportamento dessa população de forma longitudinal, de modo a analisar se esse comportamento tende a se alterar conforme a evolução da pandemia e/ou da diminuição do número de casos de Covid-19. 


\section{REFERÊNCIAS}

ACEVEDO, C. R. et al. As plataformas de streaming e seu impacto no comportamento do consumidor. Revista GEMInIS, v. 12, n. 1, p. 227-246, 2021. Disponivel em: https://www.revistageminis.ufscar.br/index. php/geminis/article/view/500/424. Acesso em: 21 set. 2021.

BURNAY, C.; RIBEIRO, N. As novas dinâmicas do consumo audiovisual em Portugal. ERC-Entidade Reguladora para a Comunicação Social. Portugal, 2016. Disponivel em: https://www.erc.pt/documentos/ Estudos/ConsumoAVemPT/ERC2016_AsNovasDinamicasConsumoAudioVisuais_web/assets/downloads/ERC2016_AsNovasDinamicasConsumoAudioVisuais.pdf. Acesso em: 19 set. 2021.

CERVO, A. L.; BERVIAN, P. A. Metodologia científica. 4. ed. São Paulo: Makron, 1996.

FERREIRA, A. da P. A invenção do rádio: um importante instrumento no contexto da disseminação da informação e do entretenimento. 2013. Disponível em: https://periodicos.ufmg.br/index.php/moci/article/ view/16969. Acesso em: 10 nov. 2020.

FRANCISCO, P. A. P.; VALENTE, M. G. (org.) Da rádio ao streaming: ECAD, direito autoral e música no Brasil. Rio de Janeiro: Beco do Azougue, 2016. Disponivel em: https://bibliotecadigital.fgv.br/dspace/ bitstream/handle/10438/17034/Da\%20r\%c3\%a1dio\%20a0\%20streaming.pdf? sequence=1\&isAllowed=y. Acesso em: 15 nov. 2020.

GIL, A. C. Métodos e técnicas de pesquisa social. 5. ed. São Paulo: Atlas, 1999.

INSTITUTO BRASILEIRO DE GEOGRAFIA E ESTATÍSTICA (IBGE). Pesquisa de Orçamentos Familiares (POF). Disponível em: http://www.ibge.gov.br/home/estatistica/populacao/condicaodevida/ pof/2019_2020/default.shtm. Acesso em: 15 nov. 2020.

ISTOÉ DINHEIRO. Streaming cresce em 2019 e gera US\$ 11 bilhões ao mercado fonográfico norte-americano. 2020. Disponivel em: https:/www.istoedinheiro.com.br/streaming-cresce-em-2019-e-gera-us-11-bilhoes-ao-mercado-fonografico-norte-americano/. Acesso em: 18 nov. 2020.

MALHOTRA, N. Pesquisa de Marketing: uma orientação aplicada. 4. ed. Porto Alegre: Bookman, 2006.

MARCONI, M. de A.; LAKATOS, E. M. Técnicas de pesquisa: planejamento e execução de pesquisas, amostragens e técnicas de pesquisa, elaboração, análise e interpretação de dados. 6. ed. São Paulo: Atlas, 2006. 
MONTEIRO, T. 0 que o consumidor busca nos streamings? 2021. Disponivel em: https://www.meioemensagem.com.br/home/midia/2021/05/28/o-que-o-consumidor-busca-nos-streamings.html. Acesso em: 25 set. 2021.

MORAES, R. Análise de Conteúdo. Educação, Porto Alegre, v. 22, n. 37, p. 7-32, 1999. Disponível em: https://edisciplinas.usp.br/pluginfile.php/4125089/mod_resource/content/1/Roque-Moraes_Analise\%20 de\%20conteudo-1999.pdf. Acesso em: 15 nov. 2020.

NUNES, Luís Filipe da Mata. Consumo de música: os social media e os serviços de streaming. 2015. Tese de Doutorado. Instituto Superior de Economia e Gestão. Disponivel em: https://www.repository.utl.pt/ bitstream/10400.5/10684/1/DM-LFMN-2015.pdf. Acesso em: 21 set. 2021.

OLIVEIRA, L. V. de et al. Do broadcasting ao streaming: variações audiovisuais do concerto sinfônico. 2019. Disponivel em: http://tede.mackenzie.br/jspui/handle/tede/4145. Acesso em: 20 set. 2021.

OLIVEIRA, T. C. L. L. de; RANIERI, P. R. As redes de streaming e a mudança no cenário de consumo de conteúdos audiovisuais. In: XIII JORNADA DE INICIAÇÃO CIENTÍFICA E VII MOSTRA DE INICIAÇÃO TECNOLÓGICA - 2017, 13., 2017, São Paulo. Anais... São Paulo: Universidade Presbiteriana Mackenzie, 2017. p. 15-29. Disponivel em: http://eventoscopq.mackenzie.br/index.php/jornada/xiiijornada/paper/ view/381/350. Acesso em: 16 nov. 2020.

OPINION BOX. Opinion box insights: streaming de vídeo. Belo Horizonte, 2020. Disponivel em: https:// d335luupugsy2.cloudfront.net/cms/files/7540/15840463880pinion_Box_Insights_-_Streaming.pdf. Acesso em: 10 nov. 2020.

POLIT, D. F.; BECK, C. T.; HUNGLER, B. P. Fundamentos de pesquisa em enfermagem.

$5^{\mathrm{a}}$ ed. Porto Alegre: Artmed; 2004.

PORTAL NACIONAL DE SEGUROS, SAÚDE, INFO, TI, EDUCAÇÃO - SEGS. Nielsen/Toluna: consumo de streaming é hábito para 43\% dos brasileiros durante a pandemia. 2020. Disponivel em: https://www. segs.com.br/demais/253698-nielsen-toluna-consumo-destreaming-e-habito-diario-para-43-dos-brasileiros-durante-a-pandemia. Acesso em: 20 set. 2021.

RICHERS, Raimar. O enigmático mas indispensável consumidor: teoria e prática. Revista de Administração, v. 19, n. 3, p. 46-56, 1984. Disponivel em: https:/www.revistas.usp.br/rausp/article/view/167512. Acesso em: 21 set. 2021. 
SANTOS, M. C. 0 rádio entre as montanhas: histórias, teorias e afetos da radiofonia mineira, 2009. Disponível em: https:/www.repositoriobib.ufc.br/00000B/00000BCC.pdf\#page=112. Acesso em: 24 set. 2021.

SILVA, M. Z; DALL'ORTO, F. C. Streaming e sua influência sobre o Audiovisual e o Product Placement. In: CONGRESSO BRASILEIRO DE CIÊNCIAS DA COMUNICAÇÃO, 40., 2017, Curitiba. Anais... Curitiba: Intercom - Sociedade Brasileira de Estudos Interdisciplinares da Comunicação, 2017. Disponivel em: https:// portalintercom.org.br/anais/nacional2017/resumos/R12-2757-1.pdf. Acesso em: 20 set. 2021.

SILVA, R. Um ano depois do início da pandemia, plataformas de streaming contabilizam ganhos.

2021. Disponível em: https://forbes.com.br/forbes-money/2021/03/um-ano-depois-do-inicio-da-pandemia-plataformas-de-streaming-contabilizam-ganhos/. Acesso em: 20 set. 2021.

SOARES, R. de L. 70 anos da televisão no Brasil e a expansão da cultura audiovisual. RuMoRes, v. 14, n. 28, p. 7-9, 2020. Disponivel em: https://www.revistas.usp.br/Rumores/article/view/177125/168120. Acesso em: 21 set. 2021.

TENDÊNCIAS. 0 impacto econômico do setor audiovisual brasileiro. São Paulo: Tendências Consultoria Integrada, 2016. Disponivel em: http://www.sicavrj.org.br/wp-content/uploads/2019/06/0-Impacto-Econ\%C3\%B4mico-do-Setor-Audiovisual-Brasileiro.pdf. Acesso em: 13 nov. 2020.

TOSTA, K. C. B. T. Pesquisa Mercadológica. 3. ed. Florianópolis: Departamento de Ciências da Administração/ufsc, 2015.

TUCCI, A. Streaming ganha ainda mais relevância com o isolamento social. 2020. Disponível em: https:/www.forbes.com.br/negocios/2020/08/streaming-ganha-ainda-mais-relevancia-com-o-isolamento-social/. Acesso em: 12 nov. 2020.

VIEIRA, M. de F. R. N.; COSTA, A. P. S. L. Oferta de produção audiovisual durante a pandemia de Covid-19: estratégias e adaptações da Rede Globo e Netflix. RuMoRes, v. 29, n. 15, p. 300-328, 2021. Disponivel em: https://www.revistas.usp.br/Rumores/article/view/185187/174715. Acesso em: 20 set. 2021.

ZALTRÃO, C. J. dos S. Resgate da memória científica nacional: a obra do padre Roberto Landell de Moura. Trabalho de Conclusão de Curso (Gestão da Informação). Setor de Ciências Sociais Aplicadas, Universidade Federal do Paraná. Curitiba, 2006. Disponível em: https://acervodigital.ufpr.br/bitstream/ handle/1884/48295/TCC\%20-\%20Claudia\%20Josiani\%20dos\%20Santos\%20Zaltrao.pdf?sequence=1\&isAllowed=y. Acesso em: 20 set. 2021. 